\title{
Problems and Countermeasures of Modern Educational Technology Practice
}

\author{
Kangning Wang ${ }^{1+}$ \\ ${ }^{1}$ Faculty of Education, Shandong Normal University, Jinan, Shandong 250014, China
}

\begin{abstract}
Modern educational technology practice highlights three misunderstandings: "the separation of theory and technology", "ethical anomie", "application first". In order to avoid and correct the biases and shortcomings of educational technology practice and then optimize the processes and results of educational technology practices, it is necessary to deeply analyze the causes of educational technology practice and provide countermeasures and strategies to alleviate and correct the problems of educational technology practice.
\end{abstract}

Keywords: educational technology, educational technology practice, problems and countermeasures

\section{Introduction}

To face and solve the practical problems of educational technology, it is necessary to make the technology practice highlight the function of technology and the value of education, which is related to the educational reform and development in the era of technology.

\section{The lack of the Premise of Educational Technology Practice}

Being different from general technology practice, the object of educational technology practice is "human". Educational technology practice is related to the development of basic education and has a profound impact on the development of students.

\subsection{The Performance of the Lack of the Premise of Educational Technology Practice}

At present, educational technology practice and educational laws and principles are not in perfect harmony and mutual promotion. Before applying educational technology, between educational technology practice and educational laws and principles, teachers tend to take one thing into consideration and lose the other. This situation is mainly reflected in two aspects. Firstly, putting the educational technology above educational laws and principles. This mainly shows that the practitioners of educational technology overemphasize and rely on educational technology. Under the guidance of the values of "focusing on development" and "efficiency first", educational technology tends to take improving the teaching efficiency of knowledge construction and ability development as the main goal, and overemphasize the significance and value of development and neglect the real experience, which is obviously not conducive to the students' emotional experience, spiritual growth and realm transformation [1].Secondly, the educational nature of educational technology is ignored. This is mainly reflected in the fact that the practitioners of educational technology pay too much attention to or even adhere to educational principles and laws, stick to the educational theory, lack of recognition of educational technology, and neglect the educational attributes of educational technology and its practical function of promoting educational development.

\subsection{The reasons for the Lack of the Premise of Educational Technology Practice}

The lack of rational premise of educational technology practice can be caused by the overemphasis of educational technology or adhering to educational principles by technical practitioners. The intervention of modern technology, from its motivation or the final effect, has a strong instrumental and auxiliary nature [2].As an auxiliary means and tool of educational practice, educational technology is introduced into

\footnotetext{
+ Corresponding author. Tel.: +8613573181313.

E-mail address: wknsdnu@163.com.
} 
educational practice because educational technology can meet people's educational needs and improve and solve educational problems to a certain extent. However, the advantages of educational technology are not enough to promote its dominant position and role. Any educational practice must be based on the following of educational laws and principles. Educational technology practice is the carrier of educational principles and laws, and represents the existence of educational principles and laws. Educational technology practice can not only verify the principles of education, but also promote people to obtain those principles and laws that are more in line with the reality of education. In educational technology practice, educational principle and educational technology are always closely related to each other, which promotes educational technology practice together.

\subsection{The Premise and Realization of Educational Technology Practice}

The main body of technological practice grasps and follows the general principles and laws of educational activities. Then Educational technological practice activities based on that can promote the maximization of technological value and function. This is the premise of "the separation of theory and technology" in educational technology practice.

In educational technology practice, "the separation of theory and technology" requires that the subject of technological practice, who understands both education and technology, is a modern person who can not only grasp and abide by educational principles, but also apply technology. Only by grasping and following educational principles can realizes the teaching objectives quickly and efficiently through the use of educational technology.

Technology and theory can be interlinked, which is a saved gospel for modern technology which is in the mire of the opposition between technology and humanity today [3].On the premise of grasping and following educational principles, using educational technology to promote the efficiency of educational activities and the optimization of educational effects is the necessary ability of educational technology practitioners and the fundamental factor to the success of technology practice.

\section{The Ethical Anomie of Educational Technology Practice}

The practical ethics of educational technology is an important part of the technical ethics and educational ethics. Educational technology practice is an important link to realize and test technology and educational ethics, and also the key to ensure the goodness of technology.

\subsection{The Performance of the Lack of Educational Technology Practice Ethics}

Educational technology has been defined by the Association for Educational Communications and Technology as the theory and practice of design, development, utilization, management and evaluation of processes and resources for learning [4]. In terms of the relationship between technology and education, the reason why educational technology practice must be ethical lies in that educational technology practice needs to safeguard the good of education all the time, and can't delete and damage it. The purpose, content and method of education all take the "goodness" as the ultimate standard and yardstick. All technologies, plans, practices and choices aim at a certain kind of good [5]. Educational technology, as various modern technologies in education, should have goodness.

However, the sollen and the real state of educational technology practice ethics are quite different. The excessive teaching information brought about by the powerful display and transmission function of media technology, the information pollution brought about by the information rubbish......" [6].The practice of unethical educational technology goes against humanity and the nature of education, and causes immeasurable and irreversible harm to people in education.

\subsection{The Reasons for the Lack of Educational Technology Practice Ethics}

The non-ethical nature of educational technology practice does not point to educational technology itself. The advocates of technology neutrality believe that the mission and responsibility of technology are given by human beings. It is the practitioners of educational technology that cause the results of non-ethical educational technology practice. In other words, unethical technology practitioners directly lead to unethical technology practice. In educational technology practice, the immoralities of technical practitioners are 
mainly manifested as: violating the principles of education and teaching, violating the characteristics and laws of physical and mental development of human beings, violating the moral norms, and the improper application of educational technology. Compared with many critiques on technology destroying ecology and leading to moral decline, it is also very urgent to correct the unethical nature of educational technology.

\subsection{The Appropriate Scale of Educational Technology Practice and its Realization Path}

The key to realize the ethics of educational technology practice is that educational technology practitioners have morality. Since the application of technology is al- ways to meet a certain need or achieve a certain purpose of people, of course, there are good and bad consequences of this application, and it has a stake in people. Thus the application of technology is of load value, which is an indisputable fact [7].Whether the subject of technology practice has noble moral quality is the basic standard to measure whether the technology practice is reasonable or not. The view- point of ensuring and endowing technology practice with ethical technology practice subject can be found in Dewey's thoughts. In view of the problem of technology ethics, Dewey put forward the view of "responsible technology". In Dewey's view, the reason why those without morality can't be the people who invent and apply technology is that the immoral people (in their basic sense) are irresponsible, his actions are unreliable, he is uncertain and unreliable. [8].In the face of technology with load value, ethical technology practitioners are the endowments and practitioners of technology ethics, and the key to ensure that the process and results of technology practice conforms to ethics.

The education without love becomes a waterless pool. Whether they are square or round, they can't escape from emptiness. [9].Education is a career with personality as its technology, and personality is the inner strength of school education Only relying on moral educational technology practitioners, can we carry out the process of moral technology practice, and then achieve the results of moral technology practice.

\section{Inappropriate Practice Principle of Educational Technology}

As the inventor, the applicator and the undertaker of the technical results, human beings determine the possibility and the degree of humanization of the technical practice.

\subsection{The Performance of Inappropriate Educational Technology Practice Principle}

Modern educational technology also has systematic and strict procedures. Educational technology, like other technologies, also realizes practical functions through instrumental rationality..... [10].The value of educational technology depends on the operation and use of educational technology. Only in the specific application process, educational technology can obtain its completion form, expand and develop itself, and show its social and cultural significance and consequences [11]. However, in front of efficient and accurate technology, human gradually becomes small and incompetent. The reality of educational technology practice is that, regardless of the original intention of technology design and the needs of educational objects, technology practitioners adhere to the principle of "application first" and play the role of technology without scruple. In the process of technology application, spirit has been devalued to recognize facts and train just for practical functions [12]. It is difficult for human's emotion, mind and spirit to influence the technical practice.

\subsection{The Causes of Inappropriate Educational Technology Prac- Tice Principles}

Technological effect depends on the mental state, mental quality or mental state of technological subject [13]. Technical practice is based on the free spiritual realm as well as the natural physical and psychological states.

The pursuit of modern education is based on the supremacy of human and psychologization, which directly shows the anticipation and control of human development. [9].Under the guidance of this concept and principle, the object of educational technology is materialized, and there are no warm-hearted people; the practitioners of educational technology blindly pursue efficiency and accuracy, and thus deviate from the educator's duty of educating people.

\subsection{The Necessary Principles and Requirements of Educational Technology Practice}


As a kind of applied knowledge and operational procedure, educational technology should not be cold and mechanical. The educational mission of educational technology makes educational technology practice to be a process of transmitting warmth and humanity. In the process of using educational technology, in order to make up the biases of "application first" and "efficiency first", the subject of technological practice should treat educational technology with self-adaptive thought and spirit, eliminate the emotional gap between the subject and object of technological practice in a perceptual way, weaken the distance between hard technology and soft humanity with his own spiritual charm and personal characteristics, and actively create a relaxed technical practice environment.

To treat educational technology with the spirit of self-adaptive thought, the technical practitioners need to maintain the initiative and vitality of the main body. Technology practitioners eliminate the emotional gap between the subject and object of technology practice in a perceptual way, in order to establish a harmonious relationship and atmosphere between "human-educational technology-human". In educational technology practice, technical practitioners with spiritual charm and personality appeal have far-reaching influence on the process and results of educational technology practice. It is an important way to give full play to the educational function of external factors and to promote the subject and object of educational technology practice to obtain positive psychological experience and good mental state.

Some scholars said: technology itself must be examined within a cultural framework, otherwise we may completely misunderstand technology [14].If we want educational technology to play its educational function, we must put it in the educational category and attribute it to the theoretical and practical framework of education. Only by using technology reasonably, controlling and guiding technology, can we hope to make our social life more satisfactory than our own [15].

Educators hold a rational attitude towards educational technology, and take the multiple identities of technology users, technology examiners and technology critics as the basis to ensure that educational technology practice reflects the discipline attribute of pedagogy, follows the theory of pedagogy, conforms to the laws of pedagogy, strictly abides by the moral norms of pedagogy and realizes the mission of education.

\section{Acknowledgment}

The author would like to express her thanks to the referee.

\section{References}

[1] L. Z. Chen and D. Y. Zhang, Inspiring and Reflecting the Educational Technology Based on Zhuang-zi's View between 'Tao' and Technique, Modern Education Technology, vol. 4, 2009, pp.18-21.

[2] S. G. Yan, Philosophy of Educational Technology, China Social Science Press, Beijing, 2015.

[3] G. S. Wu, Technology and humanity, Social Sciences of Beijing, vol. 2, 2011, pp. 90-97.

[4] Q. L. Zhou and J. J. Chen, Modern educational technology, Wuhan university press, Wu Han, 2014.

[5] Aristotle, Translated by L. T. Miao, Complete works of Aristotle, China Renmin University Press, Beijing, 1996.

[6] J. Xie and Y. Ma, Cheng Fengnong. Educational technology ethics research: theoretical perspective and content boundary, Audio visual education research, vol. 4, 2014, pp.11-16.

[7] L. Xu, Philosophy of technology, Fudan University Press, Shanghai, 2004.

[8] J. Dewey, The Collected Works of John Dewey, Southern Illinois University Press, edited by Jo Ann Boydston, 1969-1991.

[9] T. F. Liu, The eternal expectation of educational life, Hunan Press, Changsha, 2010.

[10] D. Bell, The coming of Post-Industrial society, Basic Books, 1986.

[11] B. W. Zhu, Two questions about the relationship between technology and value, Philosophical research, vol. 7, 1995, pp. 27-36.

[12] K. Jaspers, The origin and goal of history, Yale University Press, 1953.

[13] L. H. Deng, Lao Zhuang and modern technology criticism, Central Compilation and Translation Press, Beijing, 2009. 
[14] H. Poser, Translated by G. Liu, Humanistic factors and technology: facts, artifacts and interpretation, Philosophical Translation, vol. 3, 1993, pp. 71-75.

[15] C. P. Snow, The two cultures: and a second look, The New American Library, 1964. 